\title{
Ferruccio Ritossa's scientific legacy 50 years after his discovery of the heat shock response: a new view of biology, a new society, and a new journal
}

\author{
Antonio De Maio • M. Gabriella Santoro • \\ Robert M. Tanguay $\cdot$ Lawrence E. Hightower
}

Received: 16 December 2011 / Accepted: 20 December 2011 /Published online: 18 January 2012

(C) The Author(s) 2012. This article is published with open access at Springerlink.com

\begin{abstract}
The pioneering discovery of the heat shock response by the Italian scientist Ferruccio Ritossa reached maturity this year, 2012. It was 50 years ago that Professor Ritossa, through an extraordinary combination of serendipity, curiosity, knowledge and inspiration, published the first observation that cells could mount very strong transcriptional activity when exposed to elevated temperatures, which was coined the heat shock response. This discovery led to the identification of heat shock proteins, which impact many areas of current biology and medicine, and has created a new avenue for more exciting discoveries. In recognition of the discovery of the heat shock response, Cell Stress Society International (CSSI) awarded Professor Ritossa with the CSSI medallion in October 2010 in Dozza, Italy. This article is based on a session of the Fifth CSSI Congress held in Québec commemorating Professor Ritossa and his discovery.
\end{abstract}

Life is full of surprises and unexpected findings; however, nothing is discovered if you are not exploring. This thought is particularly true in science. Major findings are made when

\author{
A. De Maio $(\bowtie)$ \\ University of California San Diego, \\ La Jolla, CA 92093, USA \\ e-mail: ademaio@ucsd.edu \\ M. G. Santoro \\ University of Rome Tor Vergata, \\ 00133 Rome, Italy \\ R. M. Tanguay \\ Université Laval, \\ Quebec G1V 0A6, Canada \\ L. E. Hightower \\ University of Connecticut, \\ Storrs, CT 06269, USA
}

searching for something else. This year we celebrate the 50th anniversary of the discovery of the heat shock response by the Italian scientist, Ferruccio Ritossa, a discovery that was the perfect example of serendipity, curiosity, knowledge, and inspiration coming together to create history. The odyssey began in the early 1960s at the Genetics Institute in Pavia and at the International Institute of Genetics and Biophysics in Naples, where Ritossa was studying nucleic acid synthesis in puffs of Drosophila salivary glands. He was already a well-established investigator, considered by many to be the Italian pioneer of genetics. Ritossa chose Drosophila for his investigation because he considered it to be a model organism that is "somehow between bacteria and man." In Ritossa's own words, "many scientists were considering the work with fruit flies as not very important, secondary to phage research, which was the vogue of the time." Ritossa noticed something unexpected when cells were placed at the wrong temperature, and an incredible transcriptional activity was observed as new chromosomal puffs. Ritossa himself described the event: "I cannot remember whether it was John Pulitzer or Inge or Clara Ghini or Giordano who shifted the temperature of my incubator, but one day I noticed a different puffing pattern!" (Fig. 1). Ritossa immediately grasped its importance. As a good scientist, Ritossa repeated the experiments, included the right controls, and validated the finding (Ritossa 1996). In response to elevated temperatures, cells reacted through the synthesis of new, unknown factors.

Ritossa had a difficult time publishing the results of his unforeseen studies. Indeed, the manuscript was rejected by a highly respected journal in which the editor indicated that the studies lacked biological importance - a very familiar phrase of rejection often heard in the heat shock field, even today. The study was finally published in Experientia in 1962 (Ritossa 1962). However, the indifference to these studies 


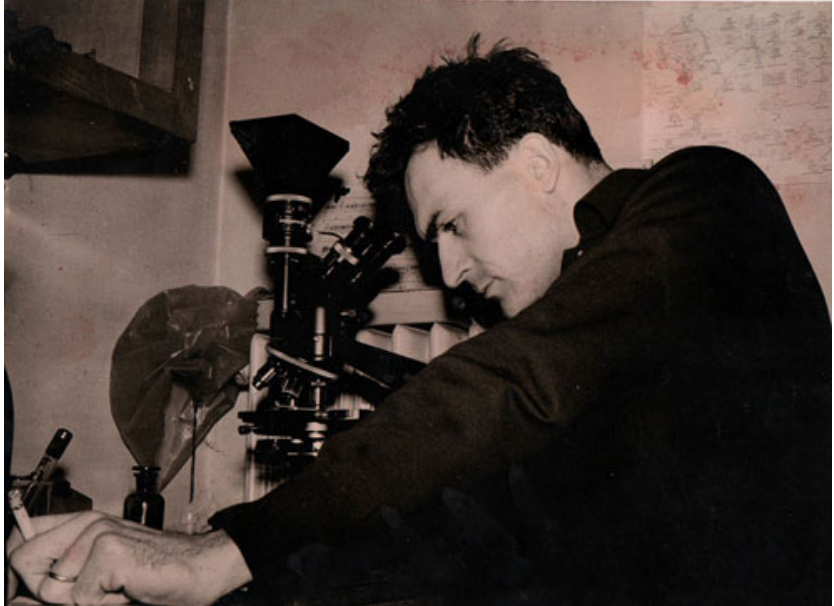

Fig. 1 Ferruccio Ritossa looking at chromosomal puffs in his laboratory in the early $1960 \mathrm{~s}$

continued for many years. It was certainly experienced by Susan Lindquist, one of the leading investigators in the field. Her decision at the beginning of her career to investigate the heat shock response in yeast was questioned by senior investigators. They did not understand why she wanted to work on an artefact. Today, we know that the heat shock response is a universal response to a large array of stresses, and that heat shock proteins, discovered 12 years later (Tissières et al. 1974), play a role in the protection from these insults. Moreover, the role of heat shock proteins has been extended to many basic cellular processes, such as protein folding, which has resulted in their denomination as molecular chaperones. The impact of the initial discovery by Ritossa has surpassed early expectations. Heat shock proteins, which have been organized into different named families (Kampinga et al. 2009), have been linked to several normal and pathological conditions. Indeed, the number of new implications for these proteins is still increasing. Heat shock proteins have been found in many cellular and molecular screenings, and we now jokingly say that they can even be found under a rock. The early controversy generated by Ritossa's finding has been a common denominator in the heat shock research field. The initial detection of extracellular heat shock proteins, their presence on the cell surface of tumor cells, their activation of immune cells, and their insertion in lipid membranes have all been added as new twists in biology, twists that were ignored for a long time and that are still controversial today despite a great number of reports (De Maio 2011).

The extraordinary finding of Ritossa has changed our vision of biology in the same way that discoveries from many other famous Italians did, such as Galileo and Golgi. However, the greatest contribution of Ritossa's discovery may have been its effect on many young scientists whose lives were changed when they chose to follow in his footsteps in the assembly of the amazing puzzle of the stress response. Ritossa's discovery set the basis for the creation of the Cell Stress Society International (CSSI), which currently has over 200 members. In addition, Ritossa's discovery was the inspiration for the development of the professional, peer-reviewed journal Cell Stress \& Chaperones, which has published over 700 articles since its inception in 1996. In summary: a new finding, a new society, and a new journal.

Ferruccio Ritossa has had an impact on us in many ways. In recognition of his pioneering discovery, the CSSI council in 2010 presented Professor Ritossa with the CSSI medallion, an award given to the greatest scientists in the field (Fig. 2). A session of the CSSI Congress held in Québec in 2011 was devoted to presentations about Professor Ritossa's legacy. Antonio De Maio's opening remarks at this session were summarized above. Summaries of the presentations of Professors Santoro, Hightower, and Tanguay follow:

\section{Ferruccio Ritossa: Gabriella Santoro's reflections}

The first time I met Ferruccio was in 1994. I was organizing a European Science Foundation Meeting in Rome on the Stress Response and thought it would be nice for Ferruccio to open the meeting. I really did not think that Ferruccio would accept the invitation since I knew that he had left science for art. In fact, after his discovery, Ferruccio spent time in the USA at Oak Ridge National Laboratory in Tennessee and the University of Illinois at Urbana, and then went back to Italy, where he was Professor of Genetics at the University of Bari and at the University of Bologna. He

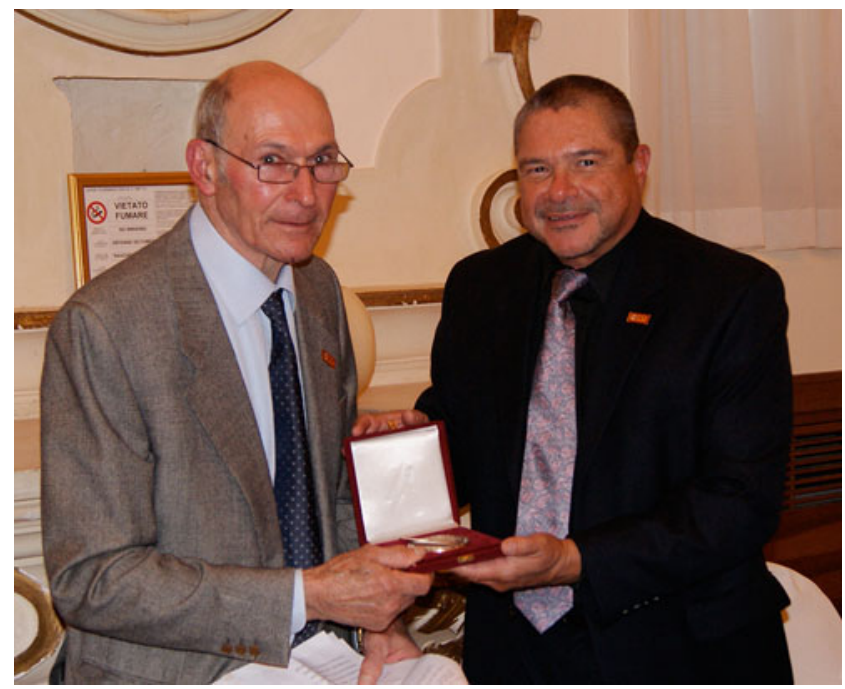

Fig. 2 CSSI President Antonio De Maio presents the CSSI medallion to Ferruccio, October 2010, in Dozza, Italy 
decided to retire quite early, in 1992, and moved to a very quiet, "non-stressful" place in the Italian Apennine Mountains near Dozza, a charming village full of history and art. There, he became a sculptor. His sculptures are fascinating: a unique mixture of nature and imagination, logic and symbols. They all convey direct messages, and some reveal the scientific imprint and show how Ferruccio is still thinking about science (Figs. 3 and 4).

Ferruccio accepted my invitation to open the meeting in Rome and gave the most fascinating speech on science and the philosophy of science, which made me appreciate him not only as a scientist but also as a human being. He was an amazing source of contagious enthusiasm with a passion for science and for life. After that, I did not see Ferruccio until recently, in October 2010, when he received the CSSI Medallion Award, which was presented to him in his hometown of Dozza. It was a very nice, simple, ceremony attended by most of his co-workers from over the years. Once again, Ferruccio gave a beautiful speech that touched on science, first of all, but also on friendship and human encounters. He talked about keeping a positive attitude to overcome obstacles and about keeping the mind focused on what your intuition urges you to follow. $\mathrm{He}$ also told us the story of how he sent the results of the discovery of the heat shock response to a highly reputable journal and how the journal editors rejected it because they considered the new finding irrelevant to the scientific community! Obviously this turned out to be an extremely nearsighted decision, considering the exceptional importance that Ferruccio's discovery has had, and continues to have, in many areas of biology, as well as its potential impact in different medical fields. How Ferruccio describes his first interpretation of the discovery of the heat shock response deserves to be mentioned: "It did not matter if this interpretation was true or false, it was a working link between imagination and reality, like love." Ferruccio is not only a scientist and an artist, he is also a poet.

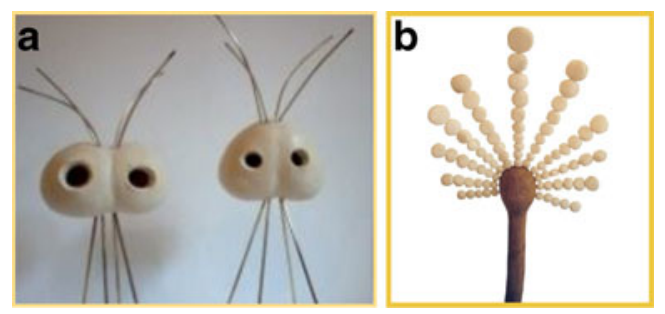

Fig. 3 Examples of sculptures by Ferruccio Ritossa. Da: Pensieri Scolpiti-Sculptured Thoughts. a "Timidi Flagellati". b "Regina di Muffe"

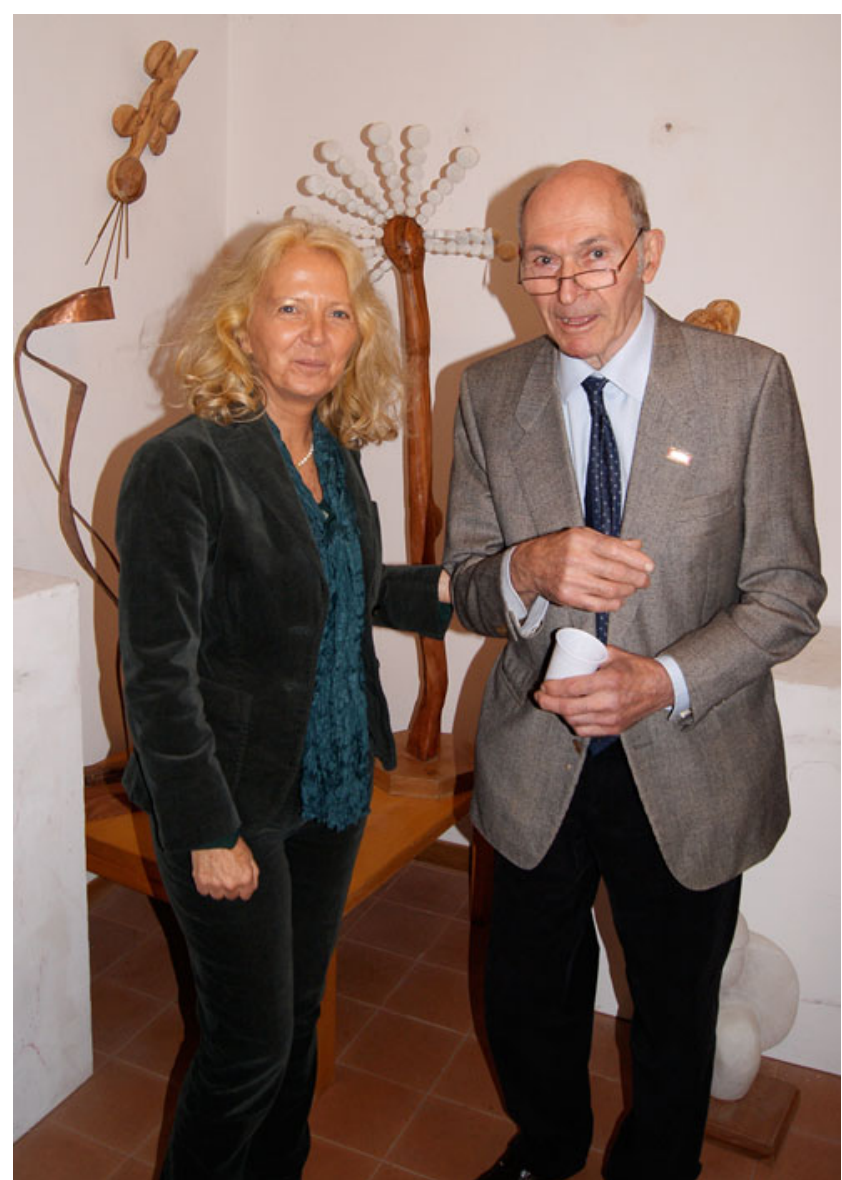

Fig. 4 Gabriella Santoro, who organized the presentation event, with Ferruccio. One of his sculptures is in the background

\section{Ferruccio Ritossa and 16 years of Cell Stress \& Chaperones: comments from Editor Lawrence E. Hightower}

Ferruccio's pioneering discovery made possible the founding of CSSI and its journal Cell Stress \& Chaperones. This is a large part of his legacy that will extend far into the future. This year, in conjunction with the commemoration of the 50th anniversary of the heat shock response discovery, we also celebrate 16 years of publication of our journal. An important element of the Ritossa legacy is that the scientists in our field serve as editors, reviewers, and authors for at least a portion of the published literature in our field. As owner of Cell Stress \& Chaperones, our society shares the publishing royalties with our publisher, Springer. These royalties are used to provide funding for meetings held around the world to promote and develop stress response research and applications and to support a new generation of cell stress scientists. Data gathered from the papers published in Cell Stress \& Chaperones provide a view of where our field is headed. For example, tracking 
the frequency and use of key words such as inflammation, vascular endothelium, and innate or natural immunity provides both a quantitative and qualitative guide to the future (Hightower 2005). The papers published in Cell Stress \& Chaperones are another source of predictions. For example, hyperbaric oxygen as an inducer of cellular stress response and possible new therapeutic applications are the topics of several recent papers. I am especially familiar with one from the Giardina laboratory titled "Hyperbaric oxygen induces a cytoprotective and angiogenic response in human microvascular endothelial cells" (Godman et al. 2010). It is clear that 50 years after Ritossa's discovery, many important new discoveries are still to be made in the stress response field. It has been my great pleasure to contribute to honoring Ferruccio Ritossa and his pioneering work on this, the 50th anniversary of the discovery of the heat shock response.

\section{A few words from CSSI President, Robert M. Tanguay}

I am particularly proud to join my colleagues in pointing out the importance of the early work of Ferruccio Ritossa. Ferruccio's discovery literally made my life - scientifically, of course. During my postdoctoral studies with J. E. Edstrom at the Karolinska Institute in Stockholm, I learned to analyze RNA in microdissected chromosome puffs (Balbiani rings) from salivary glands of another diptera, Chironomus. After my return to Canada, I looked for an induction system with which I could analyze non-histone proteins in dissected puffs following induction and/or during repression. The phosphate depletion model and the ecdysone induction were difficult to control in this diptera, so I chose to test the heat shock response that I had read about in the 1962 and 1964 papers of Ferruccio. The heat shock response in Chironomus was sizable and highly reproducible. We were thus able to report for the first time the presence of heat shock proteins within microdissected regions of the nucleus (Vincent and Tanguay 1979). The laboratory's interest immediately switched to the heat shock response, and we moved to Drosophila as it was easier to get sufficient material for biochemical analysis.

In 1981, we learned about a forthcoming meeting on heat shock to be held at the "Mecca" of Molecular Biology, the Cold Spring Harbor Laboratory. As we drove from Québec to Cold Spring Harbor, we anxiously discussed our future prospects in the field given the prestigious groups that were now working with the "artefact." A year earlier, we had submitted a grant proposal to the Cancer Society of Canada to investigate heat shock proteins in mammals and their relevance to thermotolerance. This phenomenon was well known to radiation research scientists, but the proposal was rejected with the laconic comment that heat shock proteins only existed in Drosophila and other strange insects. After arriving at Cold Spring Harbor, we attended the opening talk by Michael Ashburner, who went up to the podium with two bottles of beer in his hand. The opening talk went on late into the night, and when I went quietly to the room I had been assigned at the Osterhout, the occupant of the second bed was already there. He got up quickly and introduced himself: it was Ferruccio. We ended up talking for a long time that night. He told me how the heat shock discovery came about and how his submission to a high impact journal was rejected before his manuscript was accepted by a lesser-known Swiss journal. We moved quickly on to politics, as was natural between an engaged Italian and a Québec separatist, part of the Canadian contingent who had traveled down to the heat shock meeting. I guess that the cold up here attracted many Canadian scientists to the heat shock field! Over the following nights, I came to know more about my soon-to-be-famous roommate and about his views on life, society, and humanity. It was an inspiring encounter, and I came back to Québec full of energy to get back to the heat shock field.

My second encounter with Ferruccio's spirit was when I was invited to spend some time in Bruno Maresca's laboratory in Naples in the late 1980s. I was introduced to a real Italian research institute (International Institute of Genetics and Biophysics), which had been lodged for 32 years in "temporary" barracks next to the Naples football stadium. You could feel the buildings shake when the Naples team scored. Ferruccio was no longer at the institute, but his spirit lived on, and I learned about him as an artist from his friends there. His early work in sculpture was the subject of an exhibition under the title of LegniPietre. It assembled a dozen charming sculptures that reflected Ferruccio's humanity, humor, and love of science. I wish I could have bought a piece like "Orgasmo moleculare" while it was still possible to carry something on a plane.

The Cold Spring Harbor meeting was 30 years ago, and I still do not know what the small heat shock proteins do in a cell. This is frustrating for someone who would like to know the answer before retiring. But I am confident that the next generation of scientists will continue digging into the wide significance of Ferruccio's artefact.

\section{Concluding thoughts by Lawrence E. Hightower}

Meetings, like scientific discovery, can work in interesting and somewhat unpredictable ways. At the 1982 Cold Spring Harbor meeting, Ferruccio chaired the Inducers Session. I was the first speaker in the session, and as a young assistant professor, I was so nervous and excited about speaking in the famous Vannevar Bush lecture hall that I had forgotten that Ferruccio had chaired my session. I had no idea that heat shock proteins would become my life's work and that I would be back to the 
podium at the new Grace Auditorium several times thanks to Ferruccio's discovery. When I looked back on the abstract booklet, I found that the two roommates, Ferruccio and Robert, had been poster numbers 58 and 59 , respectively. They had been assigned as roommates based on an alphabetical listing of the first names of the abstract authors, Caizzi and Camato. It was an accidental but perfect pairing that has come full circle 30 years later. The journal in which Ferruccio's pioneering paper appeared ceased publication as Experientia in 1994 and now continues as a Springer journal with the new name Cellular and Molecular Life Sciences. Fortunately, Ferruccio's paper has a very modern Digital Object Identifier (doi:10.1007/BF02172188) to locate it in SpringerLink. None of these events were predictable any more than the remarkable spread of the heat shock response into so many areas of biology and now medicine. It is an exciting time to be part of the field that Ferruccio started because so many excellent colleagues have been attracted to it and because so much remains to be discovered.

Open Access This article is distributed under the terms of the Creative Commons Attribution Noncommercial License which permits any noncommercial use, distribution, and reproduction in any medium, provided the original author(s) and source are credited.

\section{References}

De Maio A (2011) Extracellular heat shock proteins, cellular export vesicles, and the Stress Response System: a form of communication during injury, infection, and cell damage. Cell Stress \& Chaperones $16: 235-249$

Godman CA, Chheda KP, Hightower LE, Perdizet G, Shin DG, Giardina C (2010) Hyperbaric oxygen induces a cytoprotective and angiogenic response in human microvascular endothelial cells. Cell Stress \& Chaperones 15:431-442

Hightower LE (2005) Gazing into the crystal ball: the unfolding future of molecular chaperones. In: Henderson B, Pockley AG (eds) Molecular chaperones and cell signaling. Cambridge University Press, New York, pp 321-326

Kampinga HH, Hageman J, Vos MJ, Kubota H, Tanguay RM, Bruford EA, CHeetham ME, Chen B, Hightower LE (2009) Guidelines for the nomenclature of the human heat shock proteins. Cell Stress \& Chaperones 14:105-111

Ritossa F (1962) A new puffing pattern induced by temperature shock and DNP in Drosophila. Experientia 18:571-573. doi:10.1007/ BF02172188

Ritossa F (1996) Discovery of the heat shock response. Cell Stress \& Chaperones 1:97-98

Tissières A, Mitchell HK, Tracy U (1974) Protein synthesis in salivary glands of Drosophila melanogaster. Relation to chromosome puffs. J Mol Biol 84:389-398

Vincent M, Tanguay RM (1979) Heat-shock induced proteins present in the cell nucleus of Chironomus tentans salivary glands. Nature 281:501-503 